\title{
A system for processing by digital computer spirograms acquired in field surveys
}

\author{
C. J. DERRETT and C. BROWN \\ MRC Air Pollution Unit, St Bartholomew's Hospital Medical College, Charterhouse Square, London EC1
}

\begin{abstract}
Derrett, C. J. and Brown, C. (1975). Thorax, 30, 674-677. A system for processing by digital computer spirograms acquired in field surveys. Instrumentation and techniques are described for recording expiratory spirograms in the field and analysing them with a digital computer in the laboratory. A commercially available spirometer is modified to give an oscillating electrical output signal which is recorded on a cassette tape recorder. The computer displays the spirogram, calculates the forced vital capacity, one-second forced expiratory volume, maximum mid-expiratory flow, and time to expire $25 \%, 50 \%, 75 \%$, and $90 \%$ of the vital capacity.
\end{abstract}

Investigations into the rôle of environmental or occupational factors in the development of chronic respiratory disease often require simple measurements of ventilatory capacity to be made among large, widely dispersed populations. The forced expiratory volume test is widely used in this context.

Instruments are already available that provide immediate read-out of peak flow (PF) (Wright and McKerrow, 1959), forced expiratory volume (FEV) and forced vital capacity (FVC) (McDermott, McDermott, and Collins, 1968; Beumer and Hardork, 1970; Klose, 1972; Fitzgerald, Smith, and Gaensler, 1973), but recently much attention has been paid to other more complex spirographic measures such as the maximal mid-expiratory flow (MMEF) and the time required to expire the middle half of the forced vital capacity $\left(\mathrm{FVC}_{t(0.25-0.75)}\right)$ (Allen and Sabin, 1971). These are measures of the middle part of the spirogram, which are thought to be largely independent of effort. They are considered by some workers to be of importance in studies of changes in the small airways (McFadden and Linden, 1972; Macklem, 1972). Unfortunately, they are not readily measured by simple automatic computation because the whole spirogram must be recorded before it can be analysed.

In the system described here the spirogram is recorded on magnetic tape, using inexpensive, commercially available equipment, and analysed using a laboratory digital computer.

\section{THE SPIROMETER AND VARIABLE FREQUENCY OSCILLATOR}

The spirometer we chose was the portable bellows apparatus described by McDermott et al. (1968), a $\vec{\Phi}$ instrument which had proved suitable for field surveys. The basic commercially available instrument (Gawr Electronics Inst. Ltd) is modified by mountin the volume indicator dial on the spindle of a low inertia potentiometer $\left(R_{4}\right)$ which controls the fre quency of a simple relaxation oscillator (Fig. 1).

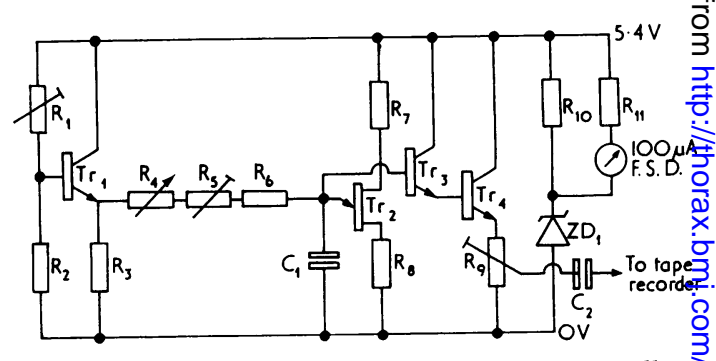

FIG. 1. Circuit diagram of variable frequency oscillatos. The output frequency is controlled by a potentiometer $\left(\mathbf{R}_{\mathbf{t}}\right)$ linked mechanically with the spirometer bellows.

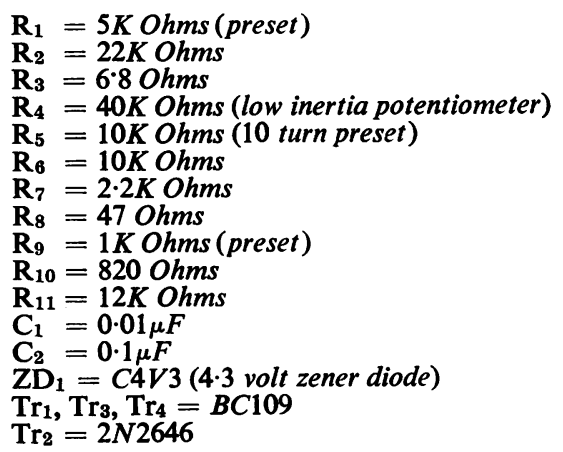


A bipolar transistor $\left(\mathrm{Tr}_{1}\right)$ provides a constant voltage supply which charges a capacitor $\left(C_{1}\right)$ via a resistor chain $\left(\mathbf{R}_{4}, \mathbf{R}_{5}\right.$, and $\left.\mathbf{R}_{6}\right)$. When the potential on the capacitor reaches a level to bias the emitter of the unijunction transistor $\left(\operatorname{Tr}_{2}\right)$ positively, the latter turns on and the capacitor discharges. The output signal has a ramp wave-form with a period of oscillation linearly proportional to the volume dial setting. We have found the system is convenient if the frequency is set at $5000 \mathrm{~Hz}$ for 0 litres on the dial and $2500 \mathrm{~Hz}$ for 5 litres. The oscillator's frequency/ volume characteristic is stable in use. Regular checking of the calibration, other than that recommended by the manufacturer of the instrument, is not necessary.

\section{THE TAPE RECORDER}

The oscillator circuit is matched to the input of a portable cassette tape recorder (National Panasonic Model RQ-212DS) by an additional pair of transistors ( $\operatorname{Tr}_{3}$ and $\operatorname{Tr}_{4}$ ) in a conventional emitter follower circuit. The tape recorder is mounted on the side of the spirometer together with the oscillator, a battery level indicator, and three push-button control switches (Fig. 2).

The quality of the recording cassettes greatly influences the performance of the instrument. Cassettes of professional quality tape with a playing

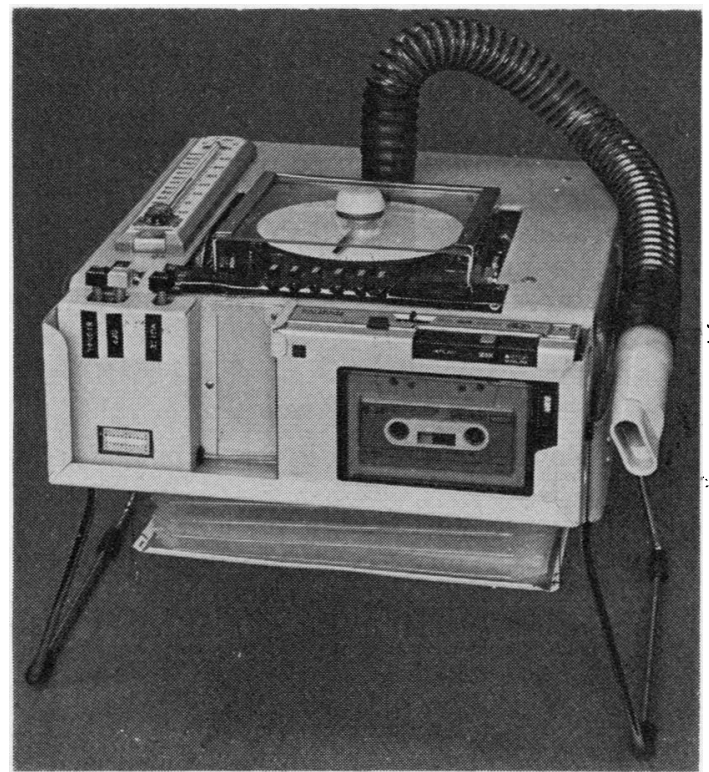

FIG. 2. The modified spirometer showing the cassette tape recorder and controls. The potentiometer $\left(\mathbf{R}_{4}\right)$ is mounted behind the dial. time of 30 minutes per side (Mallory Duratape EFR 60) are satisfactory.

THE COMPUTER AND ITS INTERFACE

The tapes are analysed using a laboratory digital computer system (Hewlett Packard 2116B). The cassette is replayed with a mains-operated tape deck (Crown CDM-11), and the frequency of the signal is converted to a series of binary numbers which are input to the computer. The frequency-digital converter and interface (Fig. 3) are made from standard electronic logic (5 volt TTL).

The replayed spirometer wave form is first converted to square wave pulses and then fed to a counter (0-127). The number of pulses counted in a period of $20 \mathrm{~ms}$ is stored by a binary latch circuit and the stored number is presented at the input of the computer. A push-button switch is also wired to one of the computer input lines to enable the operator to control the program manually. Fifteen microseconds after storing the count, the counter is reset to zero. While the next $20 \mathrm{~ms}$ count is taking place the computer is signalled that data are ready for input. They are read under control of the computer program.

OPERATING PROCEDURE Before the start of each test, a verbal announcement of the subject's name and serial number is recorded, using the microphone built into the tape recorder. The operator then switches on the oscillator and for approximately 5 seconds the 0 litre signal $(5000 \mathrm{~Hz})$ is recorded. After this has been done, the subject performs a forced expiration in the usual way. At the end of the test, or series of tests, the recorder is stopped and the tape cassette is removed for analysis.

During the analysis the tape is replayed at normal speed. The operator listens to the subject identification announcement and types the relevant information on a keyboard. When the oscillator reference signal is heard, he presses the interface push-button and the reference frequency is computed. Operation of the system is then completely automatic. The computer distinguishes the beginning and end of each spirogram and stores the data until the operator presses the button again. Then he can select whether he wishes to display the spirogram graphically (singly or superimposed on others) (Fig. 4), compute the spirogram parameters, print the results, punch the data on paper tape, or move on to a new subject.

COMPUTER PROGRAM The computer program (written in FORTRAN IV) comprises a main program handling data display, printing, and punching together with sub-routines for reading the tape 


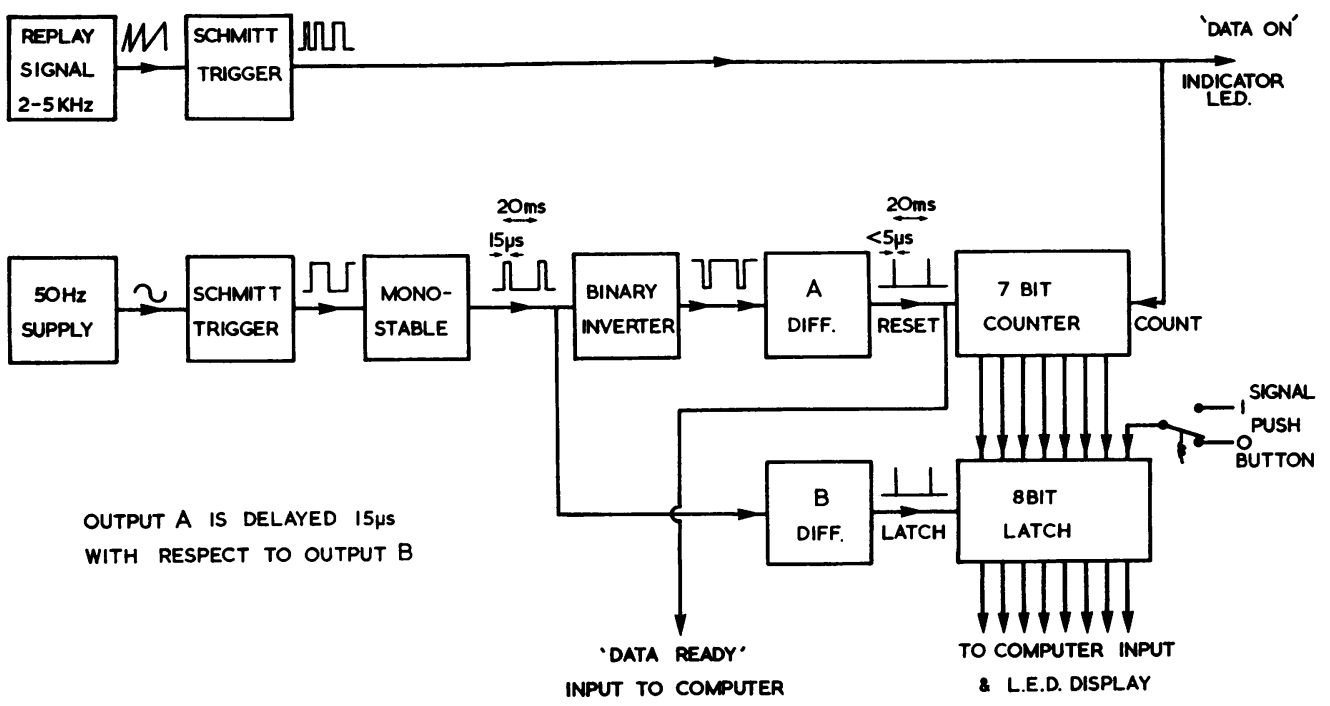

FIG. 3. Schematic diagram of frequency-digital converter and computer interface.

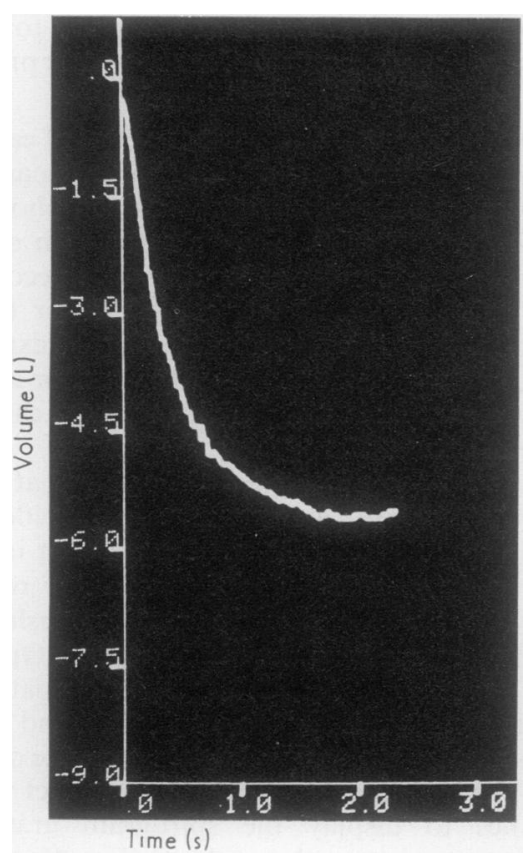

FIG. 4. A typical forced expiratory spirogram photographed from the computer's visual display unit.

player interface, sampling several sequential spirograms, and computing the spirogram parameters, FEV $_{1.0}$, FVC, MMEF, FVC $t_{t(0-0.25)}$, FVC $_{t(0-0.5)}$, $F C_{t(0-0.75)}$, and $F C_{t(0-0.9)}$.
The $5000 \mathrm{~Hz}$ reference frequency is checked by that computer during replay; a correction factor is calculated and is used to compensate for any diffe? ences between the recording and the replay speed.

The computer algorithms detecting the start an finish of forced expirations have been designed tolerate noise and tape 'drop outs' (imperfections the tape recording surface). The start of expiration $\bar{\alpha}$ recognized when the expired volume exceeds $0 \cdot \bar{B}$ litres and the end is recognized when the expired volume has remained constant for a period of at least $800 \mathrm{~ms}$.

The count is inversely proportional to the expire volume and so a change of one in the count represents a larger change in volume at high volumes than at the start of expiration. To improve the resolution at high volumes the cumulative count from a number $O$ $20 \mathrm{~ms}$ periods is used.

\section{SOURCES OF ERROR}

The main sources of error in this technique are follows:

1. Non-linearity in the dial potentiometer $\left( \pm 0.5^{\circ}\right.$

2. Quantization errors of the frequency to digit converter. These increase with volume. They are reduced by digital filtering to less than \pm 0.05 litres.

3. Wow and flutter on record and replay $(< \pm 1 \%$

4. Tape stretch and tape 'drop outs'. These max cause large errors but can be avoided if good quality tape cassettes are used and if straining of the tape during rewind is avoided.

5. Inaccuracies in the mechanical part of the 


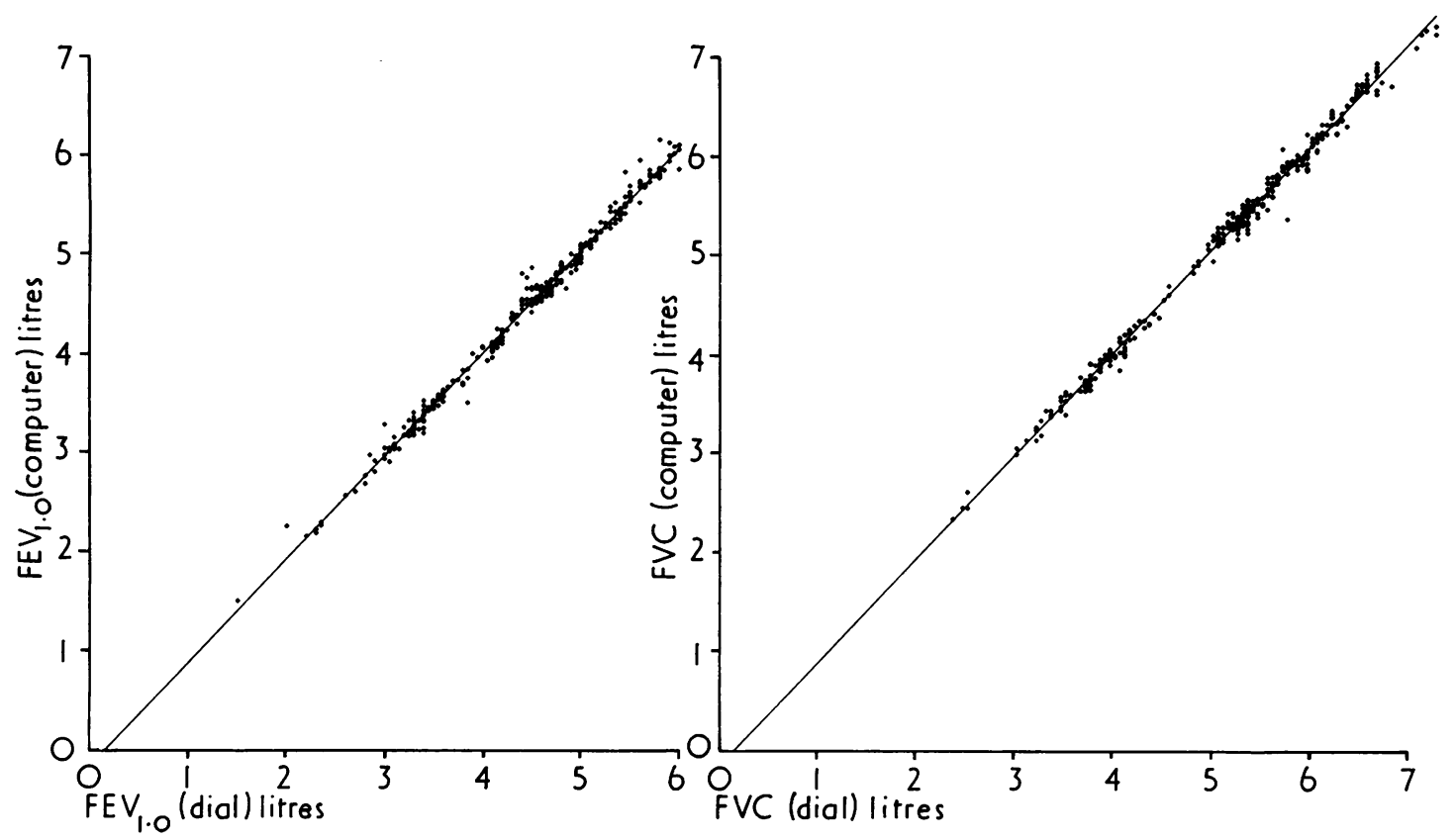

FIG. 5. Comparison of computer-calculated and operator-observed values for $\mathrm{FEV}_{1.0}$ and $\mathrm{FVC}$.

McDermott spirometer. The linearity of this should be $\pm 1 \%$ of full-scale reading.

\section{EVALUATION}

The automated part of the system was evaluated using data obtained from a group of 62 medical students. Each subject was asked to perform five forced expirations. The spirograms were recorded on the tape recorder and the values of FEV 1.0 and FVC were noted from the spirometer dial. The tape recordings were analysed using the system described. The mean of the five values of FEV 1.0 and FVC calculated by the computer $\left(\mathrm{FEV}^{\prime}{ }_{1.0}\right.$ and $\left.\mathrm{FVC}^{\prime}\right)$ were compared with those observed by the operator (FEV" ${ }_{1.0}$ and FVC") (Fig 5). For the individual values the correlation coefficients were 0.996 and 0.997 respectively. The regression equations were:

$\mathrm{FEV}^{\prime}{ }_{1.0}=1.04 \times \mathrm{FEV}^{\prime \prime}{ }_{1.0}-0.14$ (litres)

$\mathrm{FVC}^{\prime}=1.04 \times \mathrm{FVC}^{\prime \prime}-0.15$ (litres)

We believe that the technique is sufficiently accurate and consistent to be of value for both survey and clinical use. Although the digital analyser is costly, only one is needed for processing data collected with a number of spirometers.

We should like to thank our colleagues in the MRC Air Pollution Unit for advice and practical assistance. In preparing the manuscript, Professor P. J. Lawther and Miss Alison Macfarlane have been particularly helpful.

\section{REFERENCES}

Allen, G. W. and Sabin, S. (1971). Comparison of direct and indirect measurement of airway resistance. A critical analysis of the forced vital capacity curve. American Review of Respiratory Diseases, 104, 61.

Beumer, H. M. and Hardork, H. J. (1970). A mobile respiratory screening console. American Review of Respiratory Diseases, 102, 987.

Fitzgerald, M. X., Smith, A. M., and Gaensler, E. A. (1973). Evaluation of electronic spirometers. New England Journal of Medicine, 289, 1283.

Klose, R. (1972). The Spirocomp spirometric computer. Zeitschrift für praktische Anästhesie und Wiederbelebung, 7, 382.

McDermott, M., McDermott, T. J., and Collins, M. M. (1968). A portable bellows spirometer and timing unit for the measurement of respiratory function. Medical and Biological Engineering, 6, 291.

McFadden, E. R. and Linden, D. A. (1972). A reduction in maximum mid-expiratory flow rate: a spirographic manifestation of small airways disease. American Journal of Medicine, 52, 725.

Macklem, P. T. (1972). Obstruction of small airways: a challenge to medicine. American Journal of Medicine, 52, 721 .

Wright, B. M. and McKerrow, C. B. (1959). Maximum forced expiratory flow rate as a measure of ventilatory capacity. British Medical Journal, 2, 1041.

Requests for reprints to: Mr. C. J. Derrett, MRC Air Pollution Unit, St. Bartholomew's Hospital Medical College, Charterhouse Square, London EC1. 